С. М. Кузнецов, Ю. С. Косолапов, А. Д. Дармаев и др. Некоторые аспекты оптимизированного подхода при лечении паховых грыж

УДК 617.557:616-007.43

DOI: $10.18101 / 2306-1995-2020-1-57-62$

\title{
НЕКОТОРЫЕ АСПЕКТЫ ОПТИМИЗИРОВАННОГО ПОДХОДА ПРИ ЛЕЧЕНИИ ПАХОВЫХ ГРЫЖ
}

\section{(C) Кузнецов Сергей Миронович}

кандидат медицинский наук, врач хирург высшей категории, заведующий операционным отделением

s.m.kusnetzov@yandex.ru

\section{(С) Косолапов Юрий Леонидович}

подполковник медицинской службы, старший ординатор, хирург высшей категории y.kosolapov@mail.ru

\section{(C) Дармаев Андрей Дашиевич}

врач невролог высшей категории darmaevad@mail.ru

\section{(C) Гордеенок Федор Демидович} ординатор хирургического отделения, заслуженный врач России, врач высшей категории elenabotoeva@list.ru

\section{(C) Логинов Олег Станиславович}

хирург поликлинического отделения, врач высшей категории s.m.kusnetzov@yandex.ru

\section{(C) Мухутдинов Руслан Робертович} капитан медицинской службы, старший ординатор отделения хирургии s.m.kusnetzov@yandex.ru

(C) Зырянов Андрей Анатольевич ординатор отделения АиР, врач анестезиолог высшей категории s.m.kusnetzov@yandex.ru 


\title{
(C) Ващенко Павел Павлович
}

капитан медицинской службы, ординатор отделения АиР

s.m.kusnetzov@yandex.ru

\section{(C) Мицкевич Антон Сергеевич}

капитан медицинской службы, начальник отделения анестезиологии и реанимации (АиР) mits.oar38mail.ru

\section{ФГКУ «425 ВГ» Минобороны России}

филиал № 1

Россия, 664009, г. Иркутск, ул. Госпитальная, 1

\begin{abstract}
Аннотация. В статье приводятся данные по выбору методики пластики пахового канала с учетом возраста, пола, вида грыжи, технических возможностей, квалификации и опыта хирурга. Проанализировано 613 наблюдений. Чаще всего при пластике пахового канала использовалась методика Лихтенштейна $(70 \%)$ под спиномозговой анестезией. Приоритет классическим методикам отдают хирурги, имеющие значительный послужной опыт. Молодые хирурги отдают предпочтение современнымэндоскопическим методикам, но для их применения не всегда имеется достаточная техническая оснащенность и наличие современных расходных материалов.
\end{abstract}

Ключевые слова: паховая грыжа; пластика пахового канала; герниология.

\section{Для цитирования}

Некоторые аспекты оптимизированного подхода при лечение паховых грыж / С. М. Кузнецов [и др.] // Вестник Бурятского государственного университета. Медицина и формация. 2020. Вып. 1. C. $57-62$.

По обобщенной статистике большинства авторов, занимающихся современной герниологией, каждый двадцатый житель является грыженостелем. При этом более $70 \%$ имеют паховую грыжу. В связи с тем, что основная масса грыженосителей, это лица наиболее трудоспособного возраста, становится очевидной актуальность данной проблемы для хирургов. В историческом аспекте тактические и технические подходы к лечению грыж не однократно претерпевали разительные перемены. Если до 70 лет прошлого столетия основным постулатом было - при наличии косой паховой грыжи укрепляй переднюю стенку пахового канала, при прямой заднюю стенку. Для этого было разработано много методик, хотя 
С. М. Кузнецов, Ю. С. Косолапов, А. Д. Дармаев и др. Некоторые аспекты оптимизированного подхода при лечении паховых грыж

в первом случае за основу брался метод Жирар-Спасокукоцкого, во втором Бассини. В последующем подход к пластике пахового канала изменился. Пластика передней стенки пахового канала рекомендовалась только у молодых лиц, имеющих косую паховую грыжу при сохранных стенках пахового канала. В других ситуациях при наличии прямой паховой грыжи, рецидивной паховой грыжи, при косых паховых грыжах с разрушенной задней стенкой, так называемых выпрямленных косых грыж рекомендовался вариант пластики задней стенки пахового канала. В последние годы широкое распространение получили способы так называемой ненатяжной пластики дефектов с применением эксплантов. Которые в настоящее время захватили лидирующее положение. К сожалению молодые хирурги не всегда учитывают отрицательные моменты этих методов и зачастую их применяют широко у лиц молодого возраста. Так как имплантация любого инородного тела не безразлична для функционирования семенного канатика и яичка. Хирурги со стажем сдержанно относятся к данным методикам, учитывая ряд отрицательных моментов, включая нарушение кровообращения, сперматогенеза и т.д.

Два десятилетия назад нами предпочтение отдавалось традиционным методикам пластики пахового канала по Жирар-Спасокукоцкому, Бассини, Постемски. Отработанная хирургами техника операций единый подход позволили снизить процент рецидивов при первичном грыжесечении до $3,2 \%$, при наличии рецидивной грыжи до 7,4\%. Последние годы подход к пластике дефекта значительно изменился основное место в клинике занимает методика Лихтенштейна, реже Трабуко и другие эндоскопические методы.

Цель исследования: на основании ретроспективного анализа лечения паховых грыж у пациентов определить наиболее рациональные подходы к способам пластики при паховых грыжах с учетом опыта и квалификации хирургов.

Материалы и методы исследования: за пять лет в было прооперировано 613 пациентов в возрасте от 20 до 76 лет. Мужчин было 540 (88\%), женщин 73 (12\%). Значительное преобладание мужчин объясняется анатомическими особенностями паховой области у них. Основная масса грыженосителей $(72,3 \%)$ было в возрасте от 30 до 60 лет. Соотношение прямых и косых паховых грыж составило 1,3:2. При анализе отмечено значительное преобладание особенно в последние 3 года методике Лихтенштейна при грыжесечениях. Всего данная методика применена у 430 (70\%) пациентов. Основными показаниями для выполнения данной методике являлись прямые паховые грыжи, рецидивные паховые грыжи, наличие выраженного разрушения задней стенки пахового канала, а также пожилой и старческий возраст пациентов. В раннем послеоперационном 
периоде в $1(0,2 \%)$ наблюдении на 2-е сутки отмечен рецидив грыжи. Причиной рецидива явилась несостоятельность проленовых швов у лонного бугорка. Кроме того, в 3\% наблюдений отмечено формирование сером в подкожной клетчатке, которые верифицировались при УЗИ и санированы консервативными мероприятиями. Для пластики использовали отечественную проленовую сетку «этикон». Время операции практически не отличалось от продолжительности пластик по традиционным методикам.

Кроме того, в клинике было выполнено 5 пласти по Трабуко и 7 лапароскопических по Корби. Но эти две методики не получили своего широкого внедрения, первая из отсутствия соответствующих эксплантов, вторая из-за сложности выполнения и временных затрат. В 1 наблюдении после пластики по Трабуко был рецидив, возникший из-за дислокации нефиксированного протеза.

Из традиционных методик в клинике используется методика Бассини 92 (15\%) наблюдения в классическом исполнении, пластика пахового канала по Постемски в 37 (6\%) случаев и Жирар-Спасокукоцкому у 30 (5\%) пациентов. Эти методики ранее были основными для хирургической клиники и их приверженцами остаются хирурги со стажем более 25 лет. В послеоперационном периоде были отмечены серомы $2,4 \%$ и орхоэпидимит - 0,5\%, все наблюдения при рецидивных паховых грыжах. В отдельных случаях выполнялись атипичные пластики пахового канала за счет местных тканей -3 случая и по Шолдайсу -2 случая.

Операции чаще всего выполняли под спинномозговой анестезией 254 $(41,4 \%)$ случаев. Последние годы в связи с наличием эффективных фармакологических препаратов она становится в клинике ведущей. Внутривенная анестезия применялась у $96(15,6 \%)$ пациентов. В последнее время она практически не применялась. Местная анестезия использовалась у пациентов, имеющих противопоказания к другим видам обезболивания 83 $(13,5 \%)$, частота ее применения в последние годы незначительная. Эндотрахеальный наркоз применен у $68(11,1 \%)$ пациентов при отказе от спиномозговой анестезии и других ситуациях.

Выводы:

1. В последние годы приоритетной пластикой при паховых грыжах является методика Лихтенштейна (70\%), выполняемая в основном под спинномозговой анестезией $(41,4 \%)$.

2. Современные методики являются приоритетными у молодых хирургов и имеют меньший процент рецидивов и осложнений по сравнению с традиционными методиками, соответственно $0,2 \%$ и $3 \%$. 
С. М. Кузнецов, Ю. С. Косолапов, А. Д. Дармаев и др. Некоторые аспекты оптимизированного подхода при лечении паховых грыж

\section{Литература}

1. Апсатаров Э. А., Коробельников А. И. Особенности пластики пахового промежутка в зависимости от конституциональных факторов // Хирургия. 1984. № 12. С. 114-116.

2. Барышников А. И. Об эффективности применения простых способов операции при лечении паховых грыж: автореф. дис. ...д-ра мед. наук. Донецк, 1965. С. 11-15.

3. Егиев В. Н., Чижов Д. В. Использование двухслойной перфорированной пластины политетрафторэтилена при лечении паховых грыж // Хирургия. 2003. № 4. С. 23-24.

4. Жербовский В. В. Хирургия грыж живота и эвентраций. Симферополь: Бизнес Информ, 2002. 438 с.

5. Мосягина В. Б., Буряковский Д. Л., Рыбас А. В. Сравнительная оценка лапароскопического и традиционных методов лечения паховых грыж // Эндоскопическая хирургия. 2005. № 1. С. 88-89.

6. Старченков С. Б., Подолужный В. И. Технология герниопластики паховых грыж из мини-доступа // Вестник хирургии. 2007. № 5. С. 69-71.

7. Тоскин К. Д., Жербовский В. В. Хирургия грыж живота. М.: Медицина, 1983. $294 \mathrm{c}$.

8. Corbitt J. L. Laparascopic Herniorraphy: Apreperitonealtension-free approach // Surg. Endosc. 1993. № 7. C. 550-555.

9. Lichtenstein 1. L., Shulman A. G., Amid P. K., Montlior M. M. // Am. J. Surg. 1989. № 157. Pp. 188-193.

\section{SOME ASPECTS OFOPTIMIZED APPROACH}

\section{IN THE TREATMENT OF INGUINAL HERNIAS}

\section{Kuznetsov S. Mironovich}

Doctor of Higher Category, Head of Operational Department,

Sociate Professor,

s.m.kusnetzov@yandex.ru

Kosolapov Yu. Leonidovich

Lieutenant Colonel of Medical Service,

Senior Intern, Surgeon of the Highest Category

y.kosolapov@mail.ru

Darmayev A. Dashievich

Doctor Neurologist of the Highest Category

Darmaevad@Mail.Ru 
Gordeenok F. Demidovich

Resident at the Surgical Department

Honorary Doctor of Russia, Doctor of Higher Category

elenabotoeva@list.ru

Loginov O. Stanislavovich

Surgeon Polyclinic Department

Doctor of Higher Category

elenabotoeva@list.ru

Muchutdinov R. Robertowith

captain of the Medical Service Resident

at the Department of Chirurgie and Resuscitation

s.m.kusnetzov@yandex.ru

Zyryanov A. Anatolevich

resident of the Depsrtament of Anasthesiology

s.m.kusnetzov@yandex.ru

Vashchenko P. Pavlovich

captain of the Medical Service Resident

at the Department of Anesthesiology and Resuscitation

s.m.kusnetzov@yandex.ru

Miscavige A. Sergeevich

the captain of the medical service

Head of Department of Anesthesiology and resuscitation

mits.oar38mail.ru

Branch 1 Fgku «425-Vg» Mo RF

1, Hospital Str., Irkutsk, 664009, Russia

Abstract. The article provides data of the choice of plastic surgery technigues inguinal canal, taking into account the age, gender, type of hernia, technical capabilities, qualifications and experience of the surgeon. 613 observations were analised. Most often, the Lichtenstein technique was used for inguinal canal plastic surgery $(70 \%)$ under spinal anesthesia. Priority is given to classical methods by surgeons who have a significant track record/ Young surgeons the y prefer modern endoscopic technigues, but the y do not always have sufficient technical equipment and the availability of modern consumables.

Keywords: inguinal hernia; inguinal canal plastic surgery; herniology. 